Bull. Chem. Soc. Ethiop. 2019, 33(3), 551-559.

ISSN 1011-3924

(c) 2019 Chemical Society of Ethiopia and The Authors

Printed in Ethiopia

DOI: https://dx.doi.org/10.4314/bcse.v33i3.15

\title{
EFFECT OF DRYING TEMPERATURE ON POLYANILINE ELECTRODE FOR POLYANILINE|Zn BATTERY PERFORMANCE
}

\author{
Said Ali Akbar* \\ Department of Chemical Education, Serambi Mekkah University, \\ J1. Unmuha, Batoh, Lueng Bata, Kota Banda Aceh, Aceh, Indonesia, 23245
}

(Received May 4, 2019; Revised June 17, 2019; Accepted August 20, 2019)

\begin{abstract}
Here, we report the effect of various drying temperature of Polyaniline (PAni) on battery PAni|Zn performance. PAni was synthesized using the electrodeposition method on the surface of the graphite sheets (GS), at $0.7 \mathrm{~V}$ relative to the saturated $\mathrm{Ag} / \mathrm{AgCl}$. PAni is dried with various temperature, $25,80,120$, and $180{ }^{\circ} \mathrm{C}$, respectively. PAni was characterized by Raman spectroscopy; then the performance Pani battery was studied in a rechargeable battery system. The measurement results found the PAni|Zn battery with $25{ }^{\circ} \mathrm{C}$ temperature drying of PAni was a good performance which the capacity density stable at $175-105 \mathrm{mAh} \mathrm{g}^{-1}$ until 100 cycles. Raman study showed that high-temperature drying resulted in a cleavage peak at $1188 \mathrm{~cm}^{-1}$ and increased peak intensity at $1495 \mathrm{~cm}^{-1}$. This vibrational mode appears as a stretching $v(C-C)$ on the semi quinonoid ring and $v(C=N)$ on the quinoid ring. This phenomenon indicated the changing structure of PAni to be Emeraldine base form.
\end{abstract}

KEY WORDS: Aniline, Annealing, Polyaniline, Rechargeable battery, Temperature effect

\section{INTRODUCTION}

Today, with a large number of portable electronics used, such as cellular phones, personal computers, and wireless equipment in everyday life, as well as the start-up of pure electric vehicle projects, the electricity storage is more important. As one of the most common and significant storage devices for electrical energy, batteries have developed into substantial innovations that continue to grow at a more shocking and unprecedented speed [1].

Polyaniline (PAni) is one of the conductive polymers that has received much attention in its full application due to its easy synthesis route, low cost, stability in the atmospheric environment, excellent electrochemical properties, versatility, interchangeable oxidation states, and reversibility in terms of characteristics doping/dedoping acid or base. These polymers having electrical properties have aroused great interest since the 1980s, and during that time, many reports about their applications have been extensively investigated including as electronic devices [2], batteries [3], solar cells [4], sensors and actuators [5], membranes [6], anticorrosion coatings [7], and light emitting diode (LED) [8]. For batteries, PAni was widely used as anode or cathode composite material to improve conductive and catalytic properties. The PAni|Zn battery is one of the secondary batteries which mostly carried out based on PAni study as an electrode. This was due to the multilevel oxidation properties possessed by reversible PAni redox, ranging from leucoemeraldine (completely reduced state), emeraldine (half oxidized), and pernigraniline (fully oxidized state) [9]. On the other hand, Zn electrodes are cheap and easy to obtain.

The EB form is the most stable of these polymers. This condition is the most studied because the EB form could show a high conductivity level when treatment with acid given emeraldine salt (ES) form [5,7-9]. Meanwhile, the application of polyaniline depends on the morphology, polyaniline oxidation state, surface properties, thermal stability, and preparation process. There has been no study regarding the effect of PAni drying temperature synthesis on

*Corresponding author. said.aliakbar@serambimekkah.ac.id

This work is licensed under the Creative Commons Attribution 4.0 International License 
polymer stability, which is very important for further improvements to the application of battery devices. Therefore, this study was conducted on the effect of PAni electrode drying temperature on the performance of PAni|Zn batteries.

\section{EXPERIMENTAL}

Aniline was purchased from Sigma Aldrich, hydrogen chloride $37 \%$, zinc chloride $\left(\mathrm{ZnCl}_{2}\right), \mathrm{Zn}$ powder, carbon paste electrode $(\mathrm{CPE}), \mathrm{KBr}$, platinum wire $(\mathrm{Pt})$, graphite sheet $(\mathrm{GS})$, Triton $\mathrm{X}$ 100 , acetone, and $\mathrm{N}, \mathrm{N}$-dimethylacetamide (DMAC) were used as received.

The electrochemical polymerization of aniline was carried out at $0.7 \mathrm{~V}$ at room temperature in the mixed solution containing $0.40 \mathrm{M}$ aniline and $1.0 \mathrm{M} \mathrm{HCl}$. The electrolytic cell consisted of $\mathrm{Ag} / \mathrm{AgCl} /$ saturated $\mathrm{KCl}$ as a reference electrode, graphite sheet (GS) as a working electrode, and $\mathrm{Pt}$ wire net as a counter electrode. The films, obtained by the above method, were dark green. Samples product for the study were dried at $25,80,120$, and $180{ }^{\circ} \mathrm{C}$ for about $2-3 \mathrm{~h}$, then cooled down to room temperature before taking Raman measurements and applying on the PAni|Zn battery.

Raman Bruker Senterra spectrometer was used for the collection of the Raman spectra excited with a wavelength $488 \mathrm{~nm}$ laser, high resolution 1200 grooves $/ \mathrm{cm}$ grating to analyze the scattered light from the surface of the film. The power of the laser was kept low around four $\mathrm{mW}$ in other to avoid burning of the sample. The laser beam was focused on the example with the 20x (short focal) objective lens. All spectra were taken from $300 \mathrm{~cm}^{-1}$ to $3000 \mathrm{~cm}^{-1}$. The PAni|Zn battery was tested by using a galvanostatic charge/discharge cycler (Gamry Reference 3000 electroanalysis instrument) in the range of 0.7-1.6 V, with a constant current density of $2.5 \mathrm{~mA} \mathrm{~cm}^{-2}$.

\section{RESULTS AND DISCUSSION}

\section{Synthesis of PAni}

In the synthesis of PAni, many methods have been developed, both in terms of technique and the type of material used, such as X-ray irradiated polymerization, electropolymerization, interfacial polymerization and rapidly mixed. In this work, we used the electropolymerization method for PAni synthesis, the electrochemical polymerization of aniline was carried out at 0.7 $\mathrm{V}$ at room temperature in the mixed solution containing $0.40 \mathrm{M}$ aniline and $1.0 \mathrm{M}$ strong acid. The electrolytic cell consisted of a saturated $\mathrm{Ag} / \mathrm{AgCl}$ as a reference electrode. A graphite sheet (GS) was used as a working electrode and a platinum plate as a counter electrode, respectively. All potentials given here were referred to an $\mathrm{Ag} / \mathrm{AgCl}$. After this time no more polymer could adhere to the electrode, and the solution started to become Emeraldine Salt (ES) with the green color that indicating the growth of non-adhered polymer in solution (Figure 1).

In general, the polymerization of PAni mechanism takes place in several stages, namely (i) initiation, (ii) dimerization and (iii) polymerization $[17,20]$. The first step, the use of acidic media in polymerization not only to help increase the solubility of aniline but also to form anilinium species which known to be easier to oxidize compared with neutral aniline building a dication radical anilinium by releasing one electron, which balanced with aniline cation radical (Figure 2). Like the initiation stage, the dimerization stage (ii) was also a crucial stage because to obtain PAni; it was expected that each head-to-tail polymerized monomer was expected. Therefore, two mechanisms are most likely to occur because the polymerization carried out in this research was at low $\mathrm{pH}$ [10]. The first mechanism can occur between aniline cation radical species due to a low $\mathrm{pH}$ condition, and this species would be the most dominant. It is also possible that there was a neutral aniline; the dimerization could occur between aniline cation radicals and neutral aniline. The next step is the polymerization stage (propagation), which the 
dimer form will react with the existing monomers to form the polyaniline chain. Species from this dimer will dominate the distribution of the polymer, then PAni is produced in the form of emeraldine salt with dark green color [19].

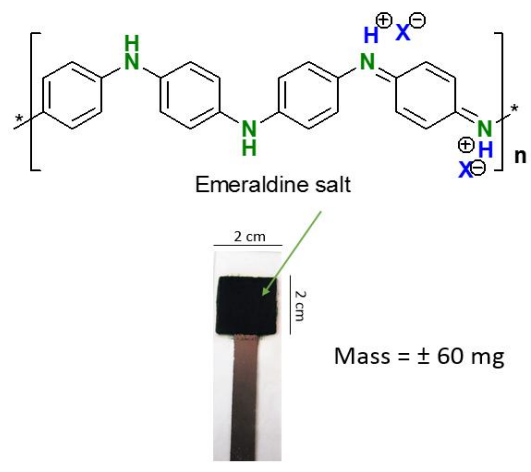

Figure 1. The PAni film was coated on GS with the area dimension $2 \mathrm{~cm} \times 2 \mathrm{~cm}$.

2

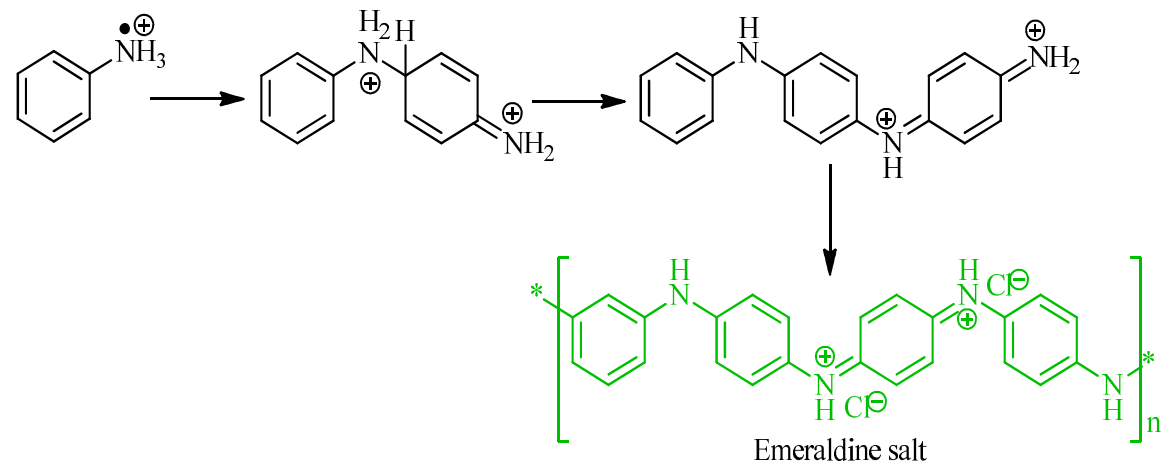

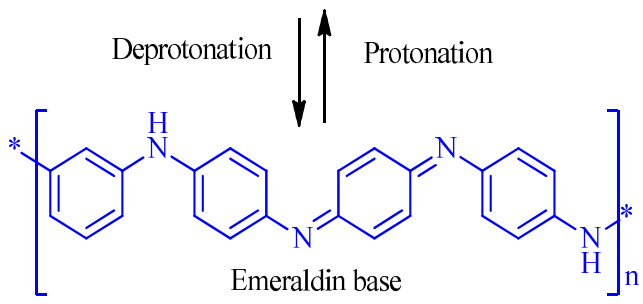

Figure 2. The route of synthesis of PAni and its protonation process in $1 \mathrm{M} \mathrm{HCl}$ solution.

\section{Characterization of PAni product}

The typical redox profile of PAni was recorded by using cyclic voltammetry (CV) with sweep rate at $50 \mathrm{mV} / \mathrm{s}$ in $1 \mathrm{M} \mathrm{HCl}$ aqueous solution (Figure 3.a). The two pairs of anodic and cathodic current peaks that appear on the voltammogram was indicated as the two kinds of redox activity on PAni. The curve between 0 and $0.25 \mathrm{~V}$ was associated with the change reaction of leucoemeraldine to the emeraldine, then the peaks occurring between 0.6 and $0.8 \mathrm{~V}$ pertains to 
the conversion of emeraldine to pernigraniline. However, the anodic peak at $0.8 \mathrm{~V}$ not appeared; it was possible the occurrence of redox competitive with the oxidation of water [3].
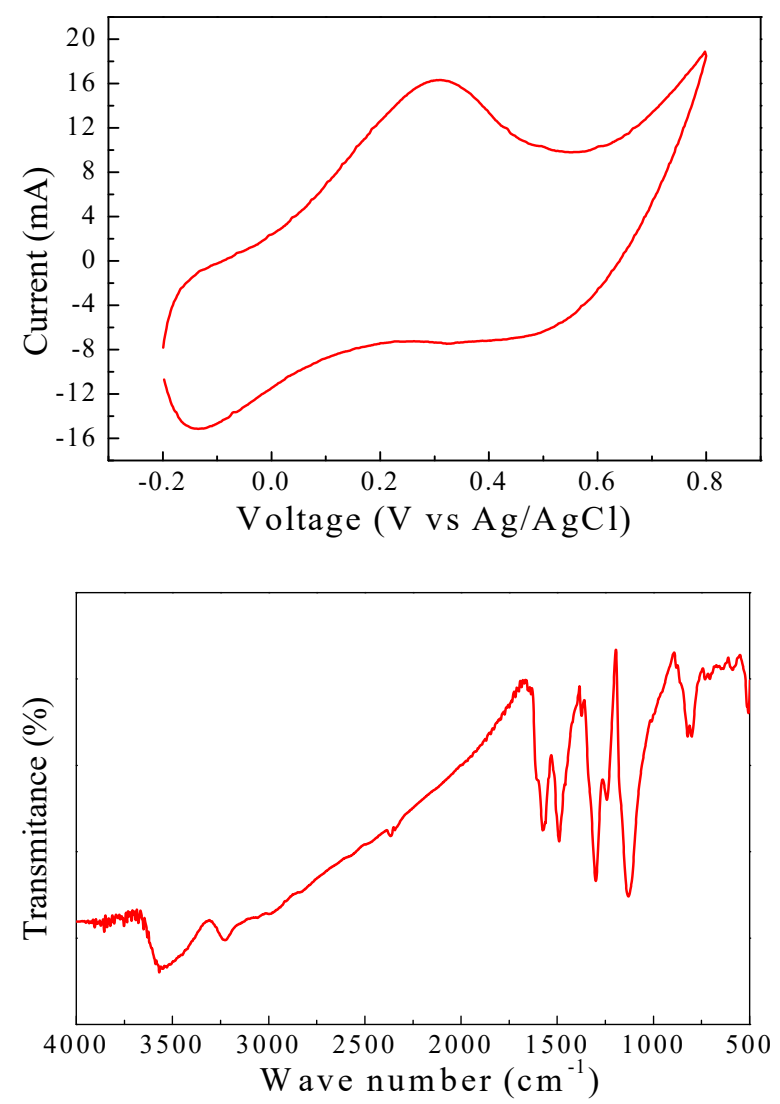

Figure 3. A characterization of PAni synthesized used (a) voltammetry (upper) and (b) FT-IR (lower).

Furthermore, the FT-IR spectrum was used to monitoring the typical vibration of PAni synthesis (Figure $3 \mathrm{~b}$ ). The stretching mode of $\mathrm{C}=\mathrm{C}$ on quinonoid (Q) and benzenoid (B) ring was respectively observed on the band at the 1560 and $1480 \mathrm{~cm}^{-1}$ regions. The peak intensity at $1480 \mathrm{~cm}^{-1}$ was seen slightly higher than at $1560 \mathrm{~cm}^{-1}$. This indicated the PAni product has a higher number of benzenoid rings than the quinoid rings. The absorption band at $1302 \mathrm{~cm}^{-1}$ corresponded to the stretching vibration of $\mathrm{C}-\mathrm{N}$ at secondary aromatic amine which was reinforced by the $\mathrm{N}-\mathrm{H}$ vibration at $3500 \mathrm{~cm}^{-1}$. The vibration appeared at $1248 \mathrm{~cm}^{-1}$ assigned as a $\mathrm{C}-\mathrm{N}^{+} \cdot$ on the polaron lattice, this band indicated the characteristic of PAni in the protonated form [18]. The strong and broadband on PANI synthesis at $1140 \mathrm{~cm}^{-1}$ was associated with the vibrations of $\mathrm{Q}=\mathrm{NH}^{+}-\mathrm{B}$ or $\mathrm{Q}-\mathrm{NH}^{++}-\mathrm{B}$ [17]. So, we can conclude that the PAni synthesis presented in emeraldine form. 


\section{Effect of various drying temperature on battery performance}

When the battery was charged, the oxidized form of PAni occurs together with increasing voltage values. Because the degradation results in an electrochemical form that is inactive when oxidation is complete, the filling process must end with a cut-off voltage (COV) reaching 1.57 $\mathrm{V}$. This problem was related to overcharge which causes an irreversible reaction (a form of electrochemical inactivity) in the chemical composition of the polymer [11, 14]. When the battery runs out at a constant current, the voltage drops slowly, then the oxidized form (emeraldine salt) of PAni changes entirely into a reduced form (leucoemeraldine). This process is limited to a voltage of $0.70 \mathrm{~V}$ to prevent overcharge as well as when charging $[10,12]$.

Based on the use of the battery (Figure 4), the PAni|Zn battery shows the highest specific capacity on PAni heating at $80{ }^{\circ} \mathrm{C}$ which is $207.6 \mathrm{mAh} \mathrm{g}^{-1}$ in the first cycle and drops sharply in the second cycle to $119.81 \mathrm{mAh} \mathrm{g}^{-1}$ to decrease regularly in the next cycle. Then, PAni|Zn also shows a high capacity on heating PAni $180{ }^{\circ} \mathrm{C}$ which is $191.70 \mathrm{mAh} \mathrm{g}^{-1}$ for the first cycle, but that capacity decreases very drastically along with the many filling-emptying cycles. On the other hand, for heating PAni which is not heated (temperature $25{ }^{\circ} \mathrm{C}$ ), shows a discharge capacity of $179.72 \mathrm{mAh} \mathrm{g}^{-1}$ with a decrease in capacity which can be said to be close to the balance in the next cycle. In comparison, capacity measurements were also made using EB PAni as an electrode on PAni|Zn batteries. From the measurement results, the capacity is around 17 $\mathrm{mAh} \mathrm{g}^{-1}$ for each cycle. From this result, the performance of PAni|Zn batteries is significantly not only affected by the cycle process, but also $\mathrm{Zn}$ 's redox kinetics is faster than PAni's electrochemical degradation. Heating with high temperatures causes PAni to be in a form that has slow degradation $[10,11,13]$.

Therefore, PAni, which is heated at $80{ }^{\circ} \mathrm{C}$ and not heated (temperature $25{ }^{\circ} \mathrm{C}$ ) shows a fair balance of capacity up to the 100 th cycle. In this case, the temperature of $25^{\circ} \mathrm{C}$ is better than the others. Even the time used for the battery discharge process at PAni $25{ }^{\circ} \mathrm{C}$ looks more extended than the others (Figure 4). This battery will be perfect to use and more durable because it saves power for longer. Capacity loss up to cycle 60 is $8.96 \%$. In the $60^{\text {th }}$ cycle, PAni's coulombic efficiency (temperature $25^{\circ} \mathrm{C}$ ) remains at $95.7 \%$, and the increase is $2.42 \%$ compared to cycle 1 . This means that the battery has a pretty good recharging performance [15].

\section{Effect various drying temperature on PAni chemical structure}

To find out the chemical bond character of the electrode on PAni, Raman spectrum measurements have been carried out to PAni with variations in the heating temperature. The results found showed considerable changes in contrast to the loss of even the emergence of new peaks in each treatment. The most exciting thing was seen in the band at $1620 \mathrm{~cm}^{-1}$ which is a stretching of $v(\mathrm{C}-\mathrm{H})$ from the semi quinonoid ring. This vibration mode is present in the presence of doping as a result of internal redox in PAni chain to form bipolaron and polaron. Then, it undergoes rearrangement to build a structure with more stable polaron (in the form of semi quinonoid) [16]. On the other hand, this allows PAni to be conductive. In Figure 5, it can be seen that the phenomenon of a decrease peak intensity with increasing heating temperature. This shown the less form of semi quinonoid found in PAni at high temperatures. 

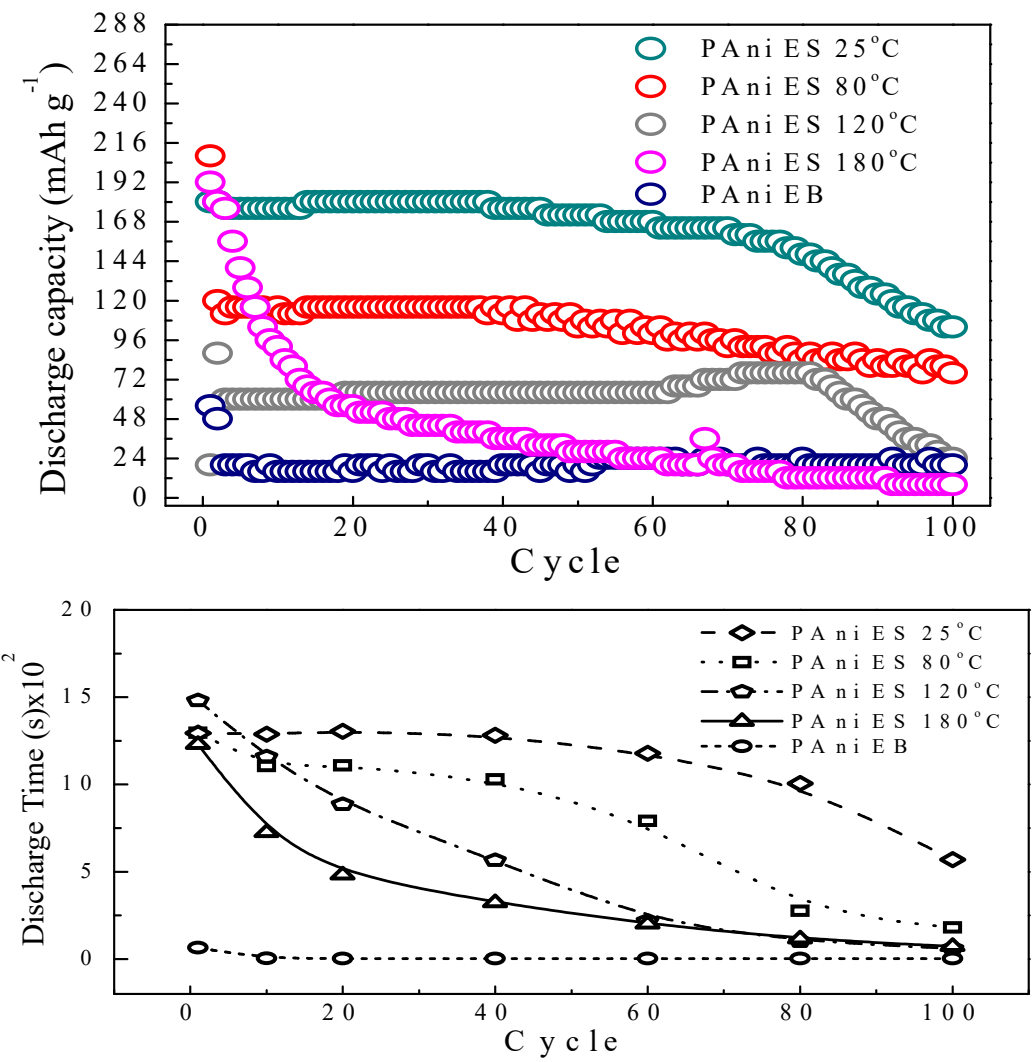

Figure 4. Discharge capacity and discharge time profiles of PANI/Zn battery at various drying temperature.

Furthermore, a decrease in peak intensity was also observed at $1192 \mathrm{~cm}^{-1}$. This vibration mode illustrated the stretching of $v(\mathrm{C}-\mathrm{C})$ that found in the semi quinonoid ring (Figure 5). This vibration undergoes simultaneous perturbation during heating; this event showed PAni experiencing doping loss. The coupling changed the conformation of the chain structure to polysemiquinoid form, which the structure is similar to the PAni on leucoemeraldine form [18, $19,21]$. Then, the band around $1100-1190 \mathrm{~cm}^{-1}$, shown the peak intensity, which slightly rises at $1167 \mathrm{~cm}^{-1}$ when the increases temperature. This wavenumber is similar to the stretching $v(\mathrm{C}-\mathrm{H})$ of PAni in Pernigraniline form [16]. This confirms that in the PAni after heating 80, 120, and $180{ }^{\circ} \mathrm{C}$, there is a quinoid ring as is the case with Pernigraniline form, whereas for PAni at 25 ${ }^{\circ} \mathrm{C}$, stretching $v(\mathrm{C}-\mathrm{H})$ was strong appeared at $1620 \mathrm{~cm}^{-1}$ which had a similar structure with leucoemeraldine form. This information is quite reliable with the loss of the exposure of PAni ES to EB. Besides, the change on the quinonoid ring to form a semi quinonoid ring is also characterized by the appearance of a vibrational peak at a $771 \mathrm{~cm}^{-1}$ shift when the temperature is getting higher. This vibrational mode is the inner deformation in the quinonoid ring field, this no longer observed at $25{ }^{\circ} \mathrm{C}$. Furthermore, PAni at $25^{\circ} \mathrm{C}$ showed high intensity in the spectrum at $817 \mathrm{~cm}^{-1}$ compared to when it was bathed. This vibration assigned to the semi quinonoid ring wagging that is affected by the vibration at 1192 and $1620 \mathrm{~cm}^{-1}$ [20]. 
Effect of drying temperature on polyaniline electrode for polyaniline | Zn battery performance 557
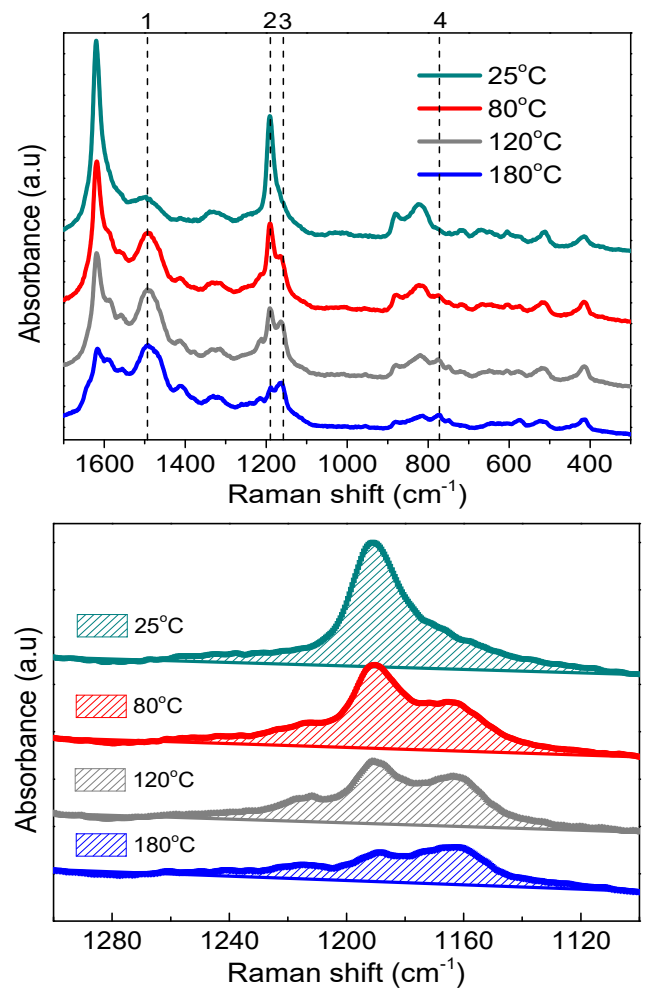

Figure 5. Raman spectra profile of PANI electrode at various drying temperature.

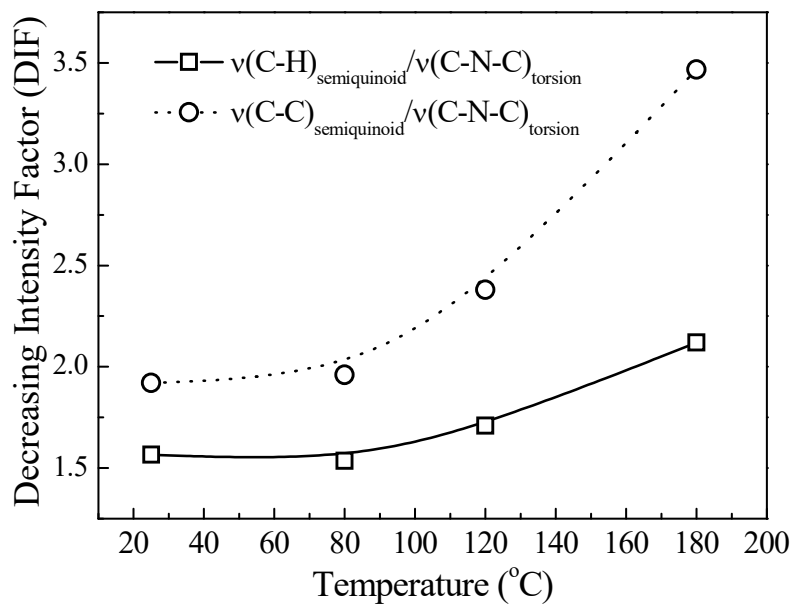

Figure 6. The ratio of DIF of semi quinonoid vibration at 1192 and $1620 \mathrm{~cm}^{-1}$ compare to torque (C-N-C). 
Stretching $v(\mathrm{C}-\mathrm{N})$ both from the secondary amine group, imine, protonated amine and amine with the polar lattice are observed in the $1200-1495 \mathrm{~cm}^{-1}$ area. The most exciting thing is the rise of the peak at $1495 \mathrm{~cm}^{-1}$ when heated at temperatures of 80,120 , and $180{ }^{\circ} \mathrm{C}$. This vibrational mode appears as stretching of $v(\mathrm{C}=\mathrm{N})$ on the quinoid ring. Also, stretching $v(\mathrm{C}=\mathrm{N})$ appears with reasonably high intensity in the form of pernigraniline. Therefore, this information is sufficient to confirm that the warming of PAni causes loss of protonation [16].

The band at $416 \mathrm{~cm}^{-1}$ was assigned a torque change of $v(\mathrm{C}-\mathrm{N}-\mathrm{C})$ which directly regulated the conformational changes of the quinonoid ring to form a semi quinonoid ring. Therefore, assuming that this torque intensity affects the vibrations strongly at 1192 and $1620 \mathrm{~cm}^{-1}$, so through comparison of intensities, the decreasing intensity factor (DIF) from the semi quinonoid peak is shown in Figure 6. Based on these data, the higher temperature would make a decrease in peak intensity so more significant.

\section{CONCLUSION}

In this work, PAni with $25^{\circ} \mathrm{C}$ and $80^{\circ} \mathrm{C}$ of annealing condition shows a fair balance of capacity up to the $100^{\text {th }}$ cycle. This battery will be excellent to use and more durable because it saves power for longer. Capacity loss up to cycle 60 is $8.96 \%$. In the $60^{\text {th }}$ cycle, PAni's coulombic efficiency (temperature $25^{\circ} \mathrm{C}$ ) remains at $95.7 \%$, and the increase is $2.42 \%$ compared to cycle 1 . Then, Raman analysis displayed the decreasing of intensity at $1620 \mathrm{~cm}^{-1}$ due to losing of semi quinonoid ring vibrational from the stretching of $v(\mathrm{C}-\mathrm{H})$. Furthermore, a decrease in peak intensity was also observed at $1192 \mathrm{~cm}^{-1}$. This vibration mode assigned the stretching of $v(\mathrm{C}-\mathrm{C})$ on the semi quinonoid ring. This information was quite strong with the loss of the exposure of PAni ES to EB.

\section{ACKNOWLEDGEMENT}

This work was supported by the DIKTI Education Scholarship 2013 and LPPM Serambi Mekkah University, thanks for its financial support in this research.

\section{REFERENCES}

1. Rochliadi, A.; Akbar, S.A.; Suendo, V. Polyaniline/Zn as secondary battery for electric vehicle base on energy return factor, Proceedings of the Joint International Conference on Electric Vehicular Technology and Industrial, Mechanical, Electrical and Chemical Engineering (ICEVT \& IMECE) 2015, Surakarta, Indonesia, 2015, 353-358. DOI: https://doi.org/10.1109/ICEVTIMECE.2015.7496686.

2. Yano, J.; Fukuoka, H.; Kitani, A. Electro-oxidation of polyaniline in the presence of electronic acceptors and the magnetic properties of the resulting polyaniline. Thin Solid Films 2016, 618, 165-171.

3. Zhao, C.; Jin, Y.; Du, X.; Du, W. In situ prepared amorphous FeCoOpolyaniline/multiwalled carbon nanotube nanohybrids as efficient oxygen evolution catalysts for rechargeable Zn-air batteries. J. Power Sources 2018, 399, 337-342.

4. Wang, Y.; Duan, J.; Zhao, Y.; Yang, X.; Tang, Q. Ternary hybrid PtM@polyaniline (M = $\mathrm{Ni}, \mathrm{FeNi}$ ) counter electrodes for dye-sensitized solar cells. Electrochim. Acta 2018, 291, 114-123.

5. Cavallo, P.; Acevedo, D.F.; Fuertes, M.C.; Soler-Illia, G.J.; Barbero, C. Understanding the sensing mechanism of polyaniline resistive sensors. Effect of humidity on sensing of organic volatiles. Sens. Actuator B-Chem. 2015, 210, 574-580.

6. Kurada, K.V.; De, S. Polyaniline doped ultrafiltration membranes: Mechanism of membrane formation and $\mathrm{pH}$ response characteristics. Polymer 2018, 153, 201-213. 
7. Li, Z.; Hu, J.; Li, Y.; Liu, J. Polyaniline/zinc/cerium nitrate pigment for epoxy based anticorrosion coatings. React. Funct. Polym. 2018, 131, $22-28$.

8. Bera, A.; Deb, K.; Kathirvel, V.; Bera, T.; Thapa, R.; Saha, B. Flexible diode of polyaniline/ITO heterojunction on PET substrate. Appl. Surf. Sci. 2017, 418(A), 264-269.

9. Gao, H.; Lu, Q.; Yao, Y.; Wang, X.; Wang, R. Significantly raising the cell performance of lithium sulfur battery via the multifunctional polyaniline binder. Electrochim. Acta 2017, 232, 414-421.

10. Xia, Y.; Zhu, D.; Si, S.; Li, D.; Wu, S. Nickel foam-supported polyaniline cathode prepared with electrophoresis for improvement of rechargeable $\mathrm{Zn}$ battery performance. J. Power Sources 2015, 283, 125-131.

11. Wu, S.; Zhao, Y.; Li, D.; Xia, Y.; Si, S. An asymmetric Zn//Ag doped polyaniline microparticle suspension flow battery with high discharge capacity. J. Power Sources 2015, 275, 305-311.

12. Zhao, Z.; Yu, T.; Miao, Y.; Zhao, X. Chloride ion-doped polyaniline/carbon nanotube nanocomposite materials as new cathodes for chloride ion battery. Electrochim. Acta 2018, 270, 30-36.

13. Jo, Y.N.; Kang, S.H.; Prasanna, K.; Eom, S.W.; Lee, C.W. Shield effect of polyaniline between zinc active material and aqueous electrolyte in zinc-air batteries. Appl. Surf. Sci. 2017, 422, 406-412.

14. Zhang, L.; Dou, P.; Wang, W.; Zheng, J.; Xu, X. Sn-Cu nanotubes enveloped in threedimensional interconnected polyaniline hydrogel framework as binder-free anode for lithium-ion battery. Appl. Surf. Sci. 2017, 423, 245-254.

15. Simotwo, S.K.; Kalra, V. Polyaniline-based electrodes: Recent application in supercapacitors and next generation rechargeable batteries. Curr. Opin. Chem. Eng. 2016, $13,150-160$.

16. Akbar, S.A.; Rochliadi, A.; Suendo, V.; Saidi, N.; Lelifajri, L.; Mardhiah, A. A Raman spectroscopy study of the polyaniline electrode on $\mathrm{Zn}$ polyaniline rechargeable batteries. Rasayan J. Chem. 2018, 11, 1525-1531.

17. Karaoğlan, N.; Bindal, C. Synthesis and optical characterization of benzene sulfonic acid doped polyaniline, Eng. Sci. Technol. Int. J. 2018, 21, 1152-1158.

18. Nascimento, D.M.D. Raman dispersion in polyaniline nanofibers Vib. Spectrosc. 2017, 90, 89-95.

19. Mažeikiené, R.; Niaura, G.; Malinauskas, A. Raman spectroelectrochemical study of polyaniline at UV, blue, and green laser line excitation in solutions of different $\mathrm{pH}$. Synth. Met. 2018, 243, 97-106.

20. Mažeikienè, R.; Niaura, G.; Malinauskas, A. Raman spectroelectrochemical study of electrode processes at hybrid polyaniline - copper hexacyanoferrate modified electrode. $J$. Electroanal. Chem. 2018, 808, 228-235.

21. Trchová, M.; Morávková, Z.; Bláha, M.; Stejskal, J. Raman spectroscopy of polyaniline and oligoaniline thin films. Electrochim. Acta 2014, 122, 28-38. 